\title{
Akut İskemik Strok Tedavisinde Hemodilüsyonun Etkinliğinin Vasomotor Reaktivite ve Serebral Oksimetre ile Değerlendirilmesi
}

\author{
Evaluation the Efficiency of Hemodilution with Vasomotor Reactivity and \\ Cerebral Oximeter in Acute Ischemic Stroke Treatment
}

\author{
${ }^{1}$ İran Yavaş, ${ }^{2}$ Demet Özbabalık Adapınar \\ ${ }^{1}$ Karabük Üniveristesi Eğitim ve Araştırma Hastanesi Nöroloji Kliniği, Karabük, Türkiye \\ ${ }^{2}$ Acıbadem Hastanesi, Nöroloji Kliniği, Eskişehir, Turkey
}

\begin{abstract}
Özet: Hemodilüsyon serebral kan akımını artırarak nöroprotektif etki göstermekte. Bu etkinin kısa ve uzun vadedeki sonuçlarını vasomotor reaktivite testi ve serebral oksimetre ile test etmeyi amaçladık. Gereç ve yöntemler: İskemik stroklu hastalar ardışık sistemle hemodilüsyon ve kontrol grubuna kabul edildi. Hemodilüsyon ilk 24 sa içinde uygulandı. Hematokrit düzeyine göre hipervolemik, izovolemik ya da hipovolemik hemodilüsyon uygulandı. Hemodilüsyon öncesi, sonrası 5.gün ve 90.gün transkranial doppler ile vasomotor reaktivite (VMR) testi, INVOS 3100 Cerebral Oximeter ile oksijen dağımı ve klinik değerlendirmeleri yapıldı. Klinik değerlendirmede Glaskow koma skalası, Bartel, Rankın, SSS, MCANS, HSS kullanıldı. Sonuçlar descriptive statistics, varyans analizi ve t- test ile değerlendirildi. Bulgular: Hemodilüsyon grubunda 21, kontrol grubunda 20 hasta vardı. Yaş ortalaması 61,2 idi. VMR testinde ve oksimetride oksijen değerlerinde iki grup birbiri ile ve günlere göre karşılaştırmada anlamlı bir farklılık bulunmamıştır. Klinik değerlendirmede 90 . Günde hemodilüsyon grubunda SSS ve MCANS değerleri daha iyi bulunmuştur. Hemodilüsyon WMR testinde ve oksijen dağılımında anlamlı bir etki göstermemiștir. Uzun dönemde klinik iyileşmede etkili bulunmuştur.
\end{abstract}

Anahtar Kelimeler: hemodilüsyon iskemik strok vasomotor reaktivite, serebral oksimetre

\begin{abstract}
Hemodilution (HD) which increases cerebral blood flow has a neuroprotective effect. We aim to test short and long term results of this effect with vasomotor reactivity test and cerebral oximetry Materials and Methods: Patients who had an ischemic stroke were included in the study consecutively. Hemodilution was performed hipervolemic, isovolemic and hypovolemic according to hematocrit levels and performed within first 24 hours. Patients underwent vasomotor reactivity test (VMR) with transcranial doppler ultrasonography, distribution of oxygen was measured with INVOS 3100 Cerebral Oximeter and simultaneous clinical assessments were done with Glascow Coma Scale, Bartel Index, Rankın Score, MCA Neurological Scale, Scandinavian Stroke Scale and Hemispheric Stroke Scale. These assessments were done in the first day, 5 days and 90 days after HD. The results were analyzed by descriptive statistics, variant analysis and t-test Result: We enrolled 21 patients whom hemodilution was performed and 20 control subjects in our study. Mean age of all subjects was 61.2 years. There was no significant difference between the two groups oxygen levels cerebral oximetry and results of vasomotor reactivity test. Hemodilution group had better clinical recovery in the third month. Hemodilution had no effect in VMR test and distribution of oxygen but it contributed to clinical recovery in long term.
\end{abstract}

Keywords: hemodilution ischemic stroke, vasomotor reactivity, cerebral oximeter

ORCID ID of the authors: İ.Y 0000-0003-2548-7305, D.Ö.A 0000-0002-3650-2876 


\section{Giriş}

Strok her y1l yirmi ölümden birinden sorumludur. Maliyet açısından değerlendirildiğinde ise uzun süren sakatlık ve yetersizliklerle beraber y1llık 34- 74 milyar dolar sağlık harcamasına neden olmaktadır.(1) Serebrovaskuler hastalıklarla ilgili araştırmacılarda daha çok serebral damarlar ya da beyin dokusu ile ilgilenilmiş, çok önemli iki faktörü kan ve akımsal (reolojik) özellikler göz ardı edilmiştir. Serebral metabolizma hızı ile bir takım hemodinamik ve hemoreolojik parametrelerin ölçümleri yapılabilmektedir. $\mathrm{Bu}$ objektif ölçümlere dayandırılan deneysel ve klinik araştırmalar, serebral iskeminin hemoreolojik yönlerini ve strok tedavisinde hemoreolojik yaklaşımların yerini açıklamada belirgin bir ilerleme sağlamaktadır(2). Hemodilüsyonun (HD) nöroprotektif etkilerini gösteren çalışmaların sayısı zamanla artmıştır. $\mathrm{Bu}$ çalışmalarda düşük molekül ağırlıklı dextran(3), albümin(4), gelatin(5), $\operatorname{HES}(6-7)$ kullanılmıştır. Hemodilüsyon ile meydana gelen hematokrit $(\mathrm{Htc})$ değerindeki düşme serebral kan akımı ve kardiak outputu artırmakta, kan viskozitesinin azalmasının direk fiziksel etkileri ve eritrosit agregasyonunda azalma meydana gelmektedir(8). İskemik stroke sonrası erken ölüm oranı ile Htc değerlerinin karşılaştırıldığ 1 bir çalışmada Htc değerleri yüksek olan kadın hastalarda mortalite oranının anlamlı olarak yüksek olduğu bildirilmiştir (9).

Akut fokal serebral iskemik bölgedeki hipoperfüzyonun düzeltilmesi amaciyla izovolomik, hipovolemik veya hipervolemik yöntemlerin kullanıldı̆̆ farklı çalışmalardan yararlı etki bildirenler yanında (10-13) ek bir yararının olmadığı şeklinde sonuçlar da bildirilmiştir.(14-18) $\mathrm{Bu}$ bilgilerin 1şığında çalışmamızda akut iskemik strok tedavisinde uygulanan HD tedavisinin serebral kan akımı, vasomotor reaktivite (VMR), serebral oksijen satursyonu üzerine etkinliğini transkranial doppler (TCD) ve serebral oksimetre yardımıyla araştırmayı amaçladık .

\section{Gereç ve Yöntem}

Kesitsel tipteki çalışmaya etik kurul onamı alındıktan sonra Osmangazi Üniversitesi Tıp Fakültesi Hastanesi nöroloji kliniğine fokal nörolojik defisit ile başvuran ve etyolojisinde iskemik strok düşünülen, aşağıdaki kriterlere uyan hastalar, çalışmaya katılma onamları alındıktan sonra, ardişık sistemle hemodilüsyon grubu (HG) ve kontrol grubuna $(\mathrm{KG})$ dahil edildi.

\section{Kabul kriterleri}

İlk 24 sa içinde başvurmak, BT ile iskemik strok tanısı almış olmak, Htc düzeyi \%38-50 arası olmak, sistolik kan basinc $<250 \mathrm{mmHg}$, diastolik kan basınc1 $<130 \mathrm{mmHg}$ arasinda olmak, antikoagulan tedavi almiyor olmak, 80 yaşın altında olmak, ileri derecede kalp yetmezliği ve aritmisi olmamak, serebrovaskuler olay öncesi günlük yaşam aktivitelerinde ve nörolojik durumunda ileri derecede yetersizliğe neden olacak şiddetli bir bozukluğu olmamak, ağrılı uyarana yanıtsız derin koma durumunda olmamak (Glasgow koma skalas1- GKS 8'in üstünde olmak).

\section{Dışlama kriterleri}

Renal yetmezlik, ileri intrakranial basınç artış1, pulmoner ödem, intraparankimal hemoraji, ileri kan beyin engeli bozukluğu, düzeltilemeyen dehidratasyon, derin subkortikal end arter infarkt1, anemisi ve kalp hastalığı olanlar (MI, anjina pektoris).

\section{Klinik değgerlendirme}

Tüm hastalardan ayrıntılı anamnez, özgeçmiş ve soygeçmiş ile ilgili öykü alındı, nörolojik ve fizik muayeneleri yapıldı. Tüm hastalara tam kan sayımı, biyokimyasal değerlendirme, fibrinojen, PT, aPTT, EKG, direk akciğer grafisi, akut ve subakut beyin görüntülemesi (BT, MRI), karotis doppler ve EKO kardiografi yapıld1. 


\section{Nörolojik değerlendirme}

Hastaların nörolojik değerlendirmesi, GKS, Hemisferik Strok Skalas1 (HSS), Bartel indeksi, Rankin Skoru, Middle Serebral Arter Nörolojik Skalası (MCANS) ve Skandinav Strok Skalası (SSS) kullanılarak 1, 5. ve 90. günlerde yapıldı.

\section{Hemodilüsyon uygulaması}

Temel prensipler; uygulama strok başlangıcından itibaren ilk 24 sa içinde başlatıldı, Htc düzeyinde $\% 15^{\prime}$ lik azalma sağlanması hedeflendi. Volüm yüklenmesine bağlı kardiak yetmezlik ve kan basıncının 160/90 mmHg'nin üzerinde olduğu durumlarda yalnizca flebotomi ile hipovolemik HD uygulandı. Başlangıç Htc değeri \%42'nin üzerinde ve kan basınc1 130/90-160/90 mmHg arasinda olan hastalarda izovolemik HD uygulandi. $\mathrm{Bu}$ işlem flebotomi ile birlikte plazma genişleticiler verilerek yapıldı. Kan basıncı 130/90 $\mathrm{mmHg}$ altında olan hastalara hipervolemik sivilar (HES $200 \% 10$ ) ilk 24 sa içinde $500 \mathrm{ml} / 30 \mathrm{dk}$ istenen $\mathrm{Htc}$ düzeyine ulaşıncaya kadar verildi. Htc düşüşünün hızlı ve yeterli düzeyde olması için çalışıldı. Düşük Htc düzeyi tekrarlanan girişimlerle akut dönem boyunca sürdürüldü.

\section{Serebral VMR testi}

2MHz'lik prob kullanılarak TCD (Multidopx4/tcd8, software, DWL elektronishe system $\mathrm{GmbH}$, Splingen) cihazı ile hasta supin pozisyonda iken orta serebral arter (MCA)'lar bilateral olarak 45-60 mm derinlik aralı̆̆ında kaydedildi. Lezyon tarafındaki akım hızları; LVMAX (maksimum akım hızı), LVD (diastolik akım hızı), LVMEAN (ortalama akım hizı), LPI (pulsatilite indeksi) ve lezyon tarafının karşısındaki kontrlateral hemisferdeki akım hızları; KVMAX, KVD, KVMEAN, KPI ölçümleri yapıldı. Ölçümler kayıt öncesi istirahatte takiben asetozolamid enjeksiyonundan $15 \mathrm{dk}$ sonra tekrarlanarak son ve ilk hız değerleri arasındaki değişim yüzdesi hesaplandı. $\mathrm{Bu}$ işlem HD öncesi 1.gün, HD sonrası 5. gün, 3. ayda yapıldı ve kaydedildi.

\section{Oksimetri ile değerlendirme}

Hemoglobinin dokuya bıraktığı oksijen saturasyonu INVOS 3000 Cerebral Oximeter cihazı kullanılarak parietal parasantral bölgeden ekstrakranial ve bilateral olarak, asetozolamid uygulaması öncesi ve sonrası lezyon tarafi (LPOX) ve kontrlateral (KPOX) tarafta ölçüldü, değerlerdeki değişim yüzdesi hesaplandı ve kaydedildi. Bu işlemler HD öncesi 1.gün, HD sonras1 5.gün ve 3. ayda yapıld 1 ve kaydedildi.

Hemodilüsyon ișlemi: HG'na seçilen hastalara ilk 24 sa içinde hemodilüsyon uygulandı. Bir hastaya hipovolemik, 15 hastaya izovolemik HD, 4 hastaya hipervolemik HD uyguland.

\section{Tedavi}

İki gruba da antiplatelet, antioksidan, antiödem ve erken dönemde hipotonik mayi tedavisi uyguland. 5.gün-3.ayda iki grubun ilaç tüketim profili aktivasyon ve rehabilitasyon programları benzerdi. Gruplar arasındaki farklı tek uygulamanın hemodilüsyon uygulaması olmasına özen gösterildi.

\section{İstatistik analiz}

İlk olarak tanımlayıcı analizler yapıldı. Sonra klinik skorlar, hematolojik parametreler, akım hızları grupların kendi içinde ve gruplar arasında t-test ile karşılaşrırıldı. Kan akım hızlarındaki değișim yüzdelerini değerlendirirken de varyans analizi ve t-test kullanıldı.

\section{Bulgular}

Çalışmaya dahil edilen 28'i erkek (15'i HG), 13'ü kadın (6'sı HG) toplam 41 hasta ardışık sistemle HG $(n=21)$ ve $K G(n=20)$ olarak iki gruba ayrıldı. Grupların sosyo-demografik ve soygeçmiş özellikleri, strok açısından risk faktörleri Tablo 1'de gösterilmiştir. Yaş

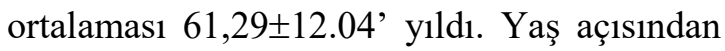
gruplar arasında istatiksel anlamlı farklılık yoktu ( $\mathrm{t}=0.562 \mathrm{sd}=39 \mathrm{p}>0.05)$. Risk faktörleri değerlendirildiğinde; KG'de 16, HG'da 9 hastada hipertansiyon (HT) mevcuttu ve aradaki fark istatiksel olarak anlamliyd 1 $(p<0.05)$. Diğer risk faktörleri ve soygeçmiş 
özellikleri açısından gruplar arasında anlamlı bir farkl1l1k saptanmadi.

Ortalama $\mathrm{Hb}$ düzeyi $\mathrm{HG}^{\prime}$ de $14.9 \pm 1 \mathrm{mg} / \mathrm{dl}$, KG'de ise $14.9 \pm 1 \mathrm{mg} / \mathrm{dl}$, ortalama Htc düzeyi HG'de 44.79 $\pm 3,23, K G$ 'de $44.28 \pm 4.2$ idi. Gruplar arasinda anlamlı farklilık yoktu ( $>>0.05)$.

Toplam 41 hastanın 27'sinin (\%65.8) (18'i HG, 9’U KG) beyin görüntülemesi normaldi.
Kalan hastalardan hepsi $\mathrm{KG}^{\prime}$ de olmak üzere 5'inde lakuner enfarkt, biri $\mathrm{HG}$, 4'ü $\mathrm{KG}$ 'de olmak üzere 5'inde büyük arter infarktı, ikisi $\mathrm{KG}$, ikisi $\mathrm{HG}$ olmak üzere 4 hastada border zone infarkt1 mevcuttu.

Tablo 1. Grubların yaş, cinsiyet, özgeçmiş, soygeçmiş dağılımı

\begin{tabular}{lccc}
\hline & TOPLAM & HG & KG \\
\hline Hasta sayısı & 41 & 21 & 20 \\
\hline Erkek & 28 & 15 & 13 \\
Kadın & 13 & 6 & 7 \\
Yaş ortalaması & 61.29 & 62.33 & 60.20 \\
Risk faktörleri & & & \\
HT & 25 & 9 & 16 \\
DM & 5 & 2 & 3 \\
Sigara & 17 & 10 & 7 \\
Alkol & 0 & 0 & 0 \\
\hline SVO & 4 & 1 & 3 \\
Kalp hastalığı & 9 & 6 & 3 \\
\hline Operasyon & 15 & 8 & 7 \\
Periferik damar hast & 4 & 2 & 2 \\
Diğer & 10 & 4 & 6 \\
Soygeçmiş & & & \\
DM & 2 & 1 & 1 \\
HT & 3 & 2 & 6 \\
\hline SVO & 8 & 2 & 1 \\
Kalp hastalığı & 5 & 4 & 1 \\
\hline Diğer & 5 & 4 & \\
\hline
\end{tabular}

Hastaların çalıșmaya alındıkları ilk gün klinik skorları her iki grup için tablo 2'de olduğu gibidir. Her bir klinik skorlama için $\mathrm{p}>0.05$ idi. Klinik skorlar açısından iki grup arasında anlamlı farklilik yoktu.

1.gün VMR sonrası HG'deki hız değişimleri, VMAX, VD, VMEAN hem lezyon tarafinda hem kontrlateralde anlamlı idi. PI değişimi her iki tarafta azalma șeklinde olmakla birlikte istatiksel olarak anlamlı değildi. POX her iki taraftada anlamlı olarak artmıştı. KG'de VMAX, VD hizları her iki tarafta anlamlı olarak arttığı görüldü. VMEAN değişiminin karşı tarafta anlamlı şekilde arttığ1, PI değerlerinin lezyon tarafinda anlamlı şekilde azaldığı, POX yüzdelerinde ise her iki tarafta anlamlı artış olduğu görüldü (Tablo 3).

Tablo2. Klinik skorların günlere göre dağılımı

\begin{tabular}{lllllll}
\hline & \multicolumn{1}{c}{ Glaskow } & \multicolumn{1}{c}{ Bartel } & \multicolumn{1}{c}{ Rankın } & \multicolumn{1}{c}{ SSS } & \multicolumn{1}{c}{ MCANS } & HSS \\
\hline 1. gün & & & & & & \\
HG & $14 \pm 2$ & $10.1 \pm 6.7$ & $3.48 \pm 1.47$ & $40.2 \pm 15.5$ & $73.1 \pm 29.9$ & $29.2 \pm 22.6$ \\
KG & $13.9 \pm 2.7$ & $9.6 \pm 5.73$ & $3.75 \pm 1.29$ & $38.3 \pm 15$ & $67.4 \pm 26.7$ & $30.4 \pm 20.1$ \\
P & $\mathrm{p}>0.05$ & $\mathrm{p}>0.05$ & $\mathrm{p}>0.05$ & $\mathrm{p}>0.05$ & $\mathrm{p}>0.05$ & $\mathrm{p}>0.05$ \\
5.gün & & & & & & \\
HG & $14.31 \pm 1.85$ & $12.06 \pm 6.44$ & $3.13 \pm 1.41$ & $44 \pm 15.09$ & $79 \pm 30.48$ & $21.47 \pm 13.82$ \\
\hline
\end{tabular}




\begin{tabular}{lllllll}
\hline KG & $14.78 \pm 0.92$ & $13.74 \pm 6.23$ & $2.89 \pm 1.56$ & $45.58 \pm 13.72$ & $79.12 \pm 23.86$ & $23.82 \pm 20.35$ \\
$\mathbf{P}$ & $\mathrm{P}>0.05$ & $\mathrm{p}>0.05$ & $\mathrm{p}>0.05$ & $\mathrm{p}>0.05$ & $\mathrm{p}>0.05$ & $\mathrm{p}>0.05$ \\
90.gün & & & & & & \\
HG & $15 \pm 0$ & $19 \pm 1.73$ & $1.69 \pm 0.95$ & $55.85 \pm 3.39$ & $104.17 \pm 1.95$ & $6.77 \pm 7.24$ \\
KG & $14.67 \pm 0.9$ & $16.6 \pm 6.11$ & $3.33 \pm 5.34$ & $44.47 \pm$ & $90.0 \pm 21.46$ & $14.53 \pm 18.71$ \\
$\mathbf{P}$ & $\mathrm{p}>0.05$ & $\mathrm{p}>0.05$ & $\mathrm{p}>0.05$ & $\mathrm{P}<0.05$ & $\mathrm{P}<0.05$ & $\mathrm{p}>0.05$ \\
\hline
\end{tabular}

Tablo 3. Grupların 1.gün WMR test sonuçlarının karşılaştırması

\begin{tabular}{|c|c|c|c|c|}
\hline HG & A öncesi & A sonrası & Değişim \% & $\mathbf{P}$ \\
\hline LVMAX & $72.31 \pm 14.81$ & $80.68 \pm 17.98$ & $14.59 \pm 8.95$ & $\mathrm{P}<0.001$ \\
\hline LVD & $26.69 \pm 6.61$ & $32.44 \pm 8.98$ & $21.47 \pm 16.97$ & $\mathrm{P}<0.001$ \\
\hline LVMEAN & $43.83 \pm 8.86$ & $52.57 \pm 12.28$ & $20.97 \pm 13.42$ & $\mathrm{p}<0.001$ \\
\hline LPI & $1.03 \pm 0.24$ & $0.95 \pm 0.16$ & $-5.26 \pm 11.7$ & $\mathrm{p}>0.05$ \\
\hline KVMAX & $78.29 \pm 17.94$ & $90.88 \pm 19.24$ & $17.43 \pm 15.17$ & $\mathrm{P}<0.001$ \\
\hline KVD & $29.35 \pm 7.77$ & $36.82 \pm 11.24$ & $25.66 \pm 18.77$ & $\mathrm{P}<0.001$ \\
\hline KVMEAN & $47.66 \pm 11.32$ & $58.11 \pm 16.69$ & $21.68 \pm 17.34$ & $\mathrm{P}<0.001$ \\
\hline KPI & $1.02 \pm 0.19$ & $0.95 \pm 0.19$ & $-6.71 \pm 9.58$ & $\mathrm{p}>0.05$ \\
\hline KG & A öncesi & A sonrası & Değişim \% & $\mathbf{P}$ \\
\hline LVMAX & $84.44 \pm 34.20$ & $95.33 \pm 34.74$ & $14.48 \pm 17.96$ & $\mathrm{P}<0.01$ \\
\hline LVD & $33.11 \pm 16.09$ & $40.16 \pm 15.99$ & $37.71 \pm 62.16$ & $\mathrm{P}<0.01$ \\
\hline LVMEAN & $74.14 \pm 86.30$ & $62.01 \pm 22.03$ & $18.69 \pm 23.63$ & $\mathrm{p}>0.05$ \\
\hline LPI & $1.0 \pm 0.34$ & $0.90 \pm 0.24$ & $-7.27 \pm 11.39$ & $\mathrm{P}<0.05$ \\
\hline KVMAX & $101.70 \pm 49.2$ & $117.88 \pm 55.03$ & $16.81 \pm 12.07$ & $\mathrm{P}<0.001$ \\
\hline KVD & $42.76 \pm 21.88$ & $50.59 \pm 24.84$ & $19.47 \pm 20.21$ & $\mathrm{P}<0.01$ \\
\hline KVMEAN & $65.73 \pm 30.3$ & $76.44 \pm 33.90$ & $17.54 \pm 15.20$ & $\mathrm{P}<0.001$ \\
\hline KPI & $0.92 \pm 0.24$ & $0.9 \pm 0.26$ & $-2.46 \pm 9.55$ & $p>0.05$ \\
\hline
\end{tabular}

VMR sonucu hızlardaki değişim yüzdeleri açısından iki grup arasında anlamlı farklılık saptanmazken, KVD A öncesi kontrlateral diastolik akım hizı $(\mathrm{t}=2.382 \mathrm{sd}=19.972 \mathrm{p}<$ 0.05), KVMEAN A öncesi kontrlateral ortalama akım hizları $(\mathrm{t}=2.441 \mathrm{sd}=22.713 \mathrm{p}<$ $0.05)$, A sonrasi KVD değerleri $(\mathrm{t}=2.081 \mathrm{sd}=$ $22.289 \mathrm{p}<0,005)$, A testi sonras KVMEAN değerleri açısından gruplar arasında anlamlı farklılık olduğu saptandı $(\mathrm{t}=2.125 \mathrm{sd}=25.937$ $\mathrm{p}<0.05)$.

Beşinci günde yapılan nörolojik değerlendirme skorları açısından gruplar arasında anlamlı farklılık saptanmadı. Labaratuar tetkik sonuçları karşılaştırıldığında, $\mathrm{Hb}$ ve $\mathrm{Htc}$ değerleri HG'de anlamlı olarak daha düşük olduğu saptand 1 (sirasiyla $\mathrm{t}=5.414 \quad \mathrm{sd}=35 \mathrm{p}<0.001$, $\mathrm{t}=4.561 \quad \mathrm{~s}=36 \quad \mathrm{p}<0.001)$. 5.gün beyin görüntülemelerinde ise 24 hastada (12'si HG, 12'si KG) lakuner enfarkt, 11 hastada (6's1 HG, 5'i KG) büyük damar enfarktı 5 hastada (2'si HG, 3'ü KG) border zone enfarktı saptand.
Grupların 5.gün yapılan VMR testi sonuçları Tablo 4'te görülmektedir. HG'de lezyon tarafinda A sonrası akım hızlarında (VMAX, VD, VMEAN) anlamlı artış saptanırken KG'de anlamlı artış görülmedi. Ancak KG'de kontrlateral akım hızlarındaki artış anlamlı bulundu. Gruplar akım hızları açısından karşılaştırıldığında ise anlamlı farklılık saptanmadi.

Birinci ve 5.gün sonuçları karşılaştırıldığında HG'de klinik skorlar tedavi öncesi değerlerden anlamlı olarak farklı değildi. Hb ve Htc değerlerinin karşılaştırması anlamlı idi (sirasiyla $\mathrm{t}=12.06 \mathrm{sd}=18 \mathrm{p}<0.001, \mathrm{t}=12.689$ $\mathrm{sd}=19 \mathrm{p}<0.001) . \mathrm{KG}$ 'da $\mathrm{Hb}$ ve Htc değerleri arasında anlamlı farklılık yokken klinik skorlar arasında anlamlı farklılık bulundu; Bartel, SSS, MCANS skorlarında anlamlı artıș (sirasiyla $\mathrm{t}=3.129 \quad \mathrm{sd}=18 \quad \mathrm{p}<0.01, \quad \mathrm{t}=2.448$ $\mathrm{sd}=18 \mathrm{p}<0.05, \quad \mathrm{t}=2.641 \quad \mathrm{sd}=16 \quad \mathrm{p}<0.018)$, Rankin skorunda anlamlı azalma olduğu görüldü ( $\mathrm{t}=2.911 \mathrm{sd}=18 \mathrm{p}<0.01)$. Glasgow ve HSS için iki grup arasında anlamlı farklılık yoktu. Birinci ve beşinci gün arasında iki grup arasındaki en önemli farklılık iskemik 
hemisferde beşinci gün kan akım hızları HG'da anlamlı artarken KG'da anlamlı bir artış görülmemesiydi.

Üçüncü ay kontrollerinde iki grup arasında $\mathrm{Hb}$ ve Htc değerleri açısından anlamlı farklılık saptanmadı. Klinik değerlendirmede Glaskow, Bartel, Rankin, HSS skorlarında anlamlı farklılık yokken SSS'da, MCANS değerlerinde anlamlı farklılık vardı (sırasıyla $\mathrm{t}=2,44 \quad \mathrm{sd}=15,18 \quad \mathrm{p}<0,05, \mathrm{t}=2,543 \quad \mathrm{sd}=14,29$ $\mathrm{p}<0,05)$ (Tablo 2).

Üçüncü ayda yapılan VMR sonucu bulunan değerler tablo 5'de özetlenmiştir. VMR sonuçları değerlendirildiğinde; HG'de lezyon tarafında ve karşı tarafta akım hızlarındaki anlamlı artış, karşı tarafta anlamlı PI değişimi, KG'de de her iki hemisferde akım hızlarında anlamlı değişim ve PI değerlerinde anlamlı azalma saptandı. Gruplar arasinda ise sadece A öncesi lezyon tarafinda serebral oksimetre değerleri (LPOX) arasında anlamlı farklılık bulundu $(\mathrm{t}=2.468 \mathrm{sd}=22 \mathrm{p}<0,05)$.
Akım hızlarının grup içi ve gruplar arası günlere göre değerlendirmesinde değişim oranları açısından anlamlı farklılık yoktu. Sadece HG'de günler arasında LVD değişimi anlamlı ve 5.günde iki grup arasında LVD değişim oranlarında anlamlı farklılık saptandı. Serebral oksimetre ile ölçülen oksijen saturasyonundaki değişimler 1., 5., 90.günlerde A öncesi ve sonrası ölçülerek değişim yüzdeleri hesaplandı. Her iki grupta günlere göre ve lezyon tarafındaki değişimler karşılaştırıldığında anlamlı bir farklılık saptanmadı. Aynı șekilde VMR sırasında karșı hemisferdeki serebral oksimetre değișimleri arasında da anlamlı bir farklılık bulunamadı.

Mortalite ve son durum: Çalışmaya katılan 2 hastaya (KG'de) daha sonra ulaşılamadı, 4 hasta (HG'de) ex oldu. Ölümleri büyük damar infarktına bağlandı. Geriye kalan 35 hasta 3.ayda hayatta idi. Bunların 23'ünde lakuner infarkt, 8'inde büyük arter infarktı, 4'ünde border zone infarkt1 mevcuttu.

Tablo 4. Grupların 5.gün VMR test sonuçlarının karşılaştırması

\begin{tabular}{lcccc}
\hline HG & A öncesi & A sonrası & Değişim \% & P \\
\hline LVMAX & $82.35 \pm 20.36$ & $96.88 \pm 23.97$ & $17.49 \pm 9.09$ & $\mathrm{P}<0.001$ \\
LVD & $29.44 \pm 10.89$ & $37.5 \pm 11.82$ & $37.69 \pm 49.49$ & $\mathrm{P}<0.001$ \\
LVMEAN & $50.23 \pm 13.23$ & $60.64 \pm 15.63$ & $20.75 \pm 9.92$ & $\mathrm{P}<0.001$ \\
LPI & $1.09 \pm 0.35$ & $0.99 \pm 0.23$ & $-6.39 \pm 10.73$ & $\mathrm{P}<0.005$ \\
KVMAX & $86.15 \pm 34.56$ & $103.87 \pm 33.30$ & $23.21 \pm 17.30$ & $\mathrm{P}<0.001$ \\
KVD & $30.87 \pm 15.90$ & $39.67 \pm 14.78$ & $89.01 \pm 238.98$ & $\mathrm{P}<0.001$ \\
\hline KVMEAN & $51.73 \pm 19.87$ & $63.26 \pm 20.06$ & $24.77 \pm 18.05$ & $\mathrm{P}<0.001$ \\
KPI & $1.08 \pm 0.30$ & $1.01 \pm 0.22$ & $-5.26 \pm 9.21$ & $\mathrm{p}>0.05$ \\
KG & & & & \\
LVMAX & $105.12 \pm 58.66$ & $110.82 \pm 49.15$ & $10.18 \pm 13.78$ & $\mathrm{P}$ \\
LVD & $43.76 \pm 28.92$ & $47.88 \pm 24.28$ & $19.10 \pm 22.67$ & $\mathrm{P}>0.05$ \\
LVMEAN & $68.84 \pm 41.7$ & $73.45 \pm 34.84$ & $12.39 \pm 16.06$ & $\mathrm{p}>0.05$ \\
LPI & $0.95 \pm 0.22$ & $0.89 \pm 0.21$ & $-5.17 \pm 10.27$ & $\mathrm{P}<0.05$ \\
KVMAX & $101.63 \pm 36.71$ & $115.47 \pm 43.61$ & $13.56 \pm 9.63$ & $\mathrm{P}<0.001$ \\
KVD & $38.0 \pm 17.13$ & $45.68 \pm 20.97$ & $22.01 \pm 27.48$ & $\mathrm{P}<0.01$ \\
KVMEAN & $62.44 \pm 25.01$ & $73.05 \pm 30.01$ & $17.32 \pm 14.15$ & $\mathrm{P}<0.001$ \\
KPI & $1.04 \pm 0.23$ & $1.01 \pm 0.31$ & $-5.43 \pm 13.76$ & $\mathrm{p}>0.05$ \\
\hline
\end{tabular}

Tablo 5. Grupların 90.gün VMR test sonuçlarının karşılaştırması

\begin{tabular}{lcccc}
\hline HG & A öncesi & A sonrası & Değişim & P \\
\hline LVMAX & $81.0 \pm 11.55$ & $96.91 \pm 17.19$ & $19.33 \pm 8.1$ & $\mathrm{P}<0.001$ \\
LVD & $32.64 \pm 7.03$ & $40.09 \pm 12.18$ & $21.96 \pm 18.53$ & $\mathrm{P}<0.01$ \\
LVMEAN & $51.05 \pm 9.03$ & $62.41 \pm 14.04$ & $21.75 \pm 11.98$ & $\mathrm{P}<0.001$ \\
LPI & $0.96 \pm 0.21$ & $0.91 \pm 0.91$ & $-4.025 \pm 9.6$ & $\mathrm{p}>0.05$ \\
\hline
\end{tabular}




\begin{tabular}{lcccc}
\hline KVMAX & $82.18 \pm 15.53$ & $100.18 \pm 23.54$ & $21.5 \pm 13.81$ & $\mathrm{P}<0.001$ \\
KVD & $31.55 \pm 6.12$ & $40.91 \pm 11.32$ & $29.44 \pm 19.91$ & $\mathrm{P}<0.001$ \\
KVMEAN & $51.43 \pm 7.67$ & $64.27 \pm 14.34$ & $24.10 \pm 14.05$ & $\mathrm{P}<0.001$ \\
\hline KPI & $0.98 \pm 0.23$ & $0.92 \pm 0.17$ & $-3.35 \pm 10.27$ & $\mathrm{P}<0.05$ \\
KG & A öncesi & A sonrası & Değişim & P \\
LVMAX & $84.69 \pm 22.91$ & $106.23 \pm 40.97$ & $23.31 \pm 21.03$ & $\mathrm{P}<0.01$ \\
LVD & $34.15 \pm 12.19$ & $45.69 \pm 20.29$ & $33.74 \pm 34.68$ & $\mathrm{P}<0.01$ \\
LVMEAN & $53.42 \pm 16.32$ & $69.53 \pm 28.20$ & $29.17 \pm 26.60$ & $\mathrm{P}<0.01$ \\
LPI & $0.96 \pm 0.25$ & $0.88 \pm 0.20$ & $-7.65 \pm 11.28$ & $\mathrm{P}<0.05$ \\
KVMAX & $89.21 \pm 27.93$ & $112 \pm 44.36$ & $24.19 \pm 17.9$ & $\mathrm{P}<0.01$ \\
KVD & $36.43 \pm 12.55$ & $50.64 \pm 24.20$ & $36.98 \pm 31.02$ & $\mathrm{P}<0.01$ \\
KVMEAN & $57.01 \pm 18.31$ & $75.07 \pm 32.14$ & $30.13 \pm 22.21$ & $\mathrm{P}<0.01$ \\
KPI & $0.92 \pm 0.21$ & $0.83 \pm 0.19$ & $-8.83 \pm 12.35$ & $\mathrm{P}<0.05$ \\
\hline
\end{tabular}

\section{Tartışma}

Hemodilüsyon, özellikle otoregulasyonun yetersiz olduğu iskemik beyin dokusunda $\mathrm{Htc}$ ve fibrinojen değerlerini düşürüp perfuzyon basıncını artırarak etkili olur (19). Deneysel çalışmalarda, normovolomik hemodilusyonun infarkt volümünü azalttığ1 ve nörolojik iyileşmeyi sağladığı gösterilirken (7) klinik çalışmalar bu sonuçları destekleyememiştir (18).

HD çalıșmalarında daha çok HES kullanılmakta olup tedaviye başlama zamanları farklılık göstermektedir. Hayvan deneylerinde ilk 3 sa içinde uygulanırken klinik çalışmalarda 6 sa -24 sa hatta 48 saat içinde uygulandığ 1 bildirilmiştir. Çalışmamızda ilk 6 sa içinde uygulama yapılmadığından hemodilüsyonun erken dönemdeki etkileri değerlendirilemedi. Tedaviye başlama zamanı gibi Htc değerinde ne kadarlık bir düşüş hedeflendiği ile ilgili de çalışmalar arasında farklılık mevcuttur. Ancak Htc değerinde \% $15^{\prime}$ lik bir azalma să̆lamanın viskoziteyi azaltıp serebral kan akımında artış oluşturduğu gösterilmiştir.(20) Bizim çalışmamızda \%16.6 oranında gerçekleşen düşüş bu veriler doğrultusunda değerlendirildiğinde anlamlı ve başarılı bir düzeydedir. Farklı olarak Xiong L. ve ark.'nın çalışmasında ise Htc dilüsyon oranı $\% 20$ olduğunda iskemik hasarın artacağ 1 \%25-30 arasında olduğunda ise nöroprotektif olacağ 1 sonucuna varılmıştır (7). Penubranın oksijenasyonu için gerekli optimal $\mathrm{Hb}$ değeriyle ilgili belirlenmiş bir düzey yoktur. $\mathrm{Hb}$ ve Htc düzeyinde düșüs ile akut iskemik strokta kötü prognoz ve ölüm arasında bağlantı gösteren çalışmalar vardır (21). Bazı hemodilüsyon çalışmalarında aşırı düşüş nedeniyle yüksek morbidite ve mortalite oranları bulunmuş ve tamamlanmadan sonlandırılmıştır (15-22) Çalışmamızda uyguladığımız hemodilusyon metodu hastalardaki kan basincı ile Htc düzeylerini dikkate alarak standardize edilmiș bir yöntem olup etkili Htc azalması yanısıra minimal hipovolemi ve kardiyovasküler risk amaçlanmıştır.

Çalışmamızda hemodilüsyon ve kontrol grubuna kabul edilen hastaların çalışmanın başlangıcında klinik skorlar, özgeçmiş, hematolojik test sonuçları, beyin damar kan akım hızları açısından benzer olması karşılaştırma sonuçlarını daha da anlamlı kılmıştır. Klinik değerler açısından iyileşme akut dönemde KG'de MCANS, SSS, Rankın, Bartel'de belirgin farklıydı. Kronik dönemde ise HG'da SSS ve MCANS belirgin daha yüksekti. Her iki grup akut dönemde iyileşme açısından birbirinden farklı değildi. Kronik dönemde ise SSS, MCANS HG'de üçüncü ay değerleri anlamlı bir şekilde yüksekti. Bu sonuç hemodilusyonun yararlı olmadığını gösteren çalışmaların aksine (23) klinik yararlılığının uzun dönemde olduğunu düşündürmektedir.

Beyin görüntülemelerine bakıldığında daha önceki çalışmaların aksine belli bir alan infarktı olanlar çalışmaya alınarak sınırlandırma yapılmamıs, kriterlere uyan ve iskemik serebral olay düșünülen tüm hastalar çalışmaya dahil edilmiştir. HG'de 12 hasta lakuner, 8 hasta büyük arter infarktına (6 hasta büyük arter, 2 hasta border zone) sahipti. $\mathrm{KG}^{\prime}$ de ise 12 hasta lakuner infarkt, 8 hasta büyük alan infarktına sahipti (5 hasta büyük arter infarktı, 3 hasta border zone infarktı). 
Beyin görüntülemesi ile klinik skorlar arasındaki ilişkiye bakıldığında $\mathrm{HG}^{\prime}$ de 1.gün sadece Rankın skorları ile beyin görüntülemesi arasında anlamlı bir ilişki saptanırken 5.gün ve 90.gündekideğerlendirmelerde klinik skorlar ile beyin görüntülemesi arasında anlamlı bir ilişki görülmedi. KG'de ise 1.gün Rankın, Bartel, SSS, MCANS, HSS değerleri ile beyin görüntülemesi arasında anlamlı ilişki saptandı, 5.gün Bartel, Rankın, SSS, MCANS, HSS, 90.gün MCANS, HSS skorlar1 ise lakuner infarkt grubunda daha iyiydi. KG hastalarda lakuner infarktı olanların klinik skorlarının daha iyi olması doğal bir sonuçtur. HG hastalarında infarkt alanı ile klinik durum arasında bir ilişki olmaması hemodilüsyonun infarkt alanına göre farklı bir etkisi olmadığını göstermektedir.

Çalışmamızda daha önce hemodilüsyon çalışmalarında yapılmamış dinamik bir test olan VMR testi uygulandi. TCD yardımıyla akım hızları ölçüldü ve A uygulanıp $15 \mathrm{dk}$ sonra kan akımındaki değişime bakıldı. Değişimlerin yüzdeleri iki grup arasında karşılaştırıldığında; 1.gün tedavi öncesi VMR testinde her iki grupta da kan akım hızlarının arttığ1 ancak gruplar arasında anlamlı bir farklılık olmadığ 1 saptandı. Sadece KG'de A sonras1 noniskemik hemisferde diastolik ve ortalama akım hızları HG'na göre daha yüksek bulundu. Test 5.gün yapıldığında ise HG'de kan akım hızlarında anlamlı bir artış gözlenirken, $\mathrm{KG}$ 'de iskemik taraftaki kan akım hızlarında anlamlı bir artış meydana gelmedi. Akım hızları tek tek karşılaştırıldığında ise iki grup arasında fark saptanmadı. Üç ay sonra yapılan değerlendirmede hem HG hem de KG'de VMR testinde kan akım hızlarında anlamlı artış görüldü. İki gruptaki değişimler karşılaştırıldığında ise bir fark bulunmadı.
HG'de iskemik hemisferde 5.gün diastolik kan akımında görülen değişim 1.gün , 90.gün ve KG ile karşılaştırıldığında anlamlı olarak yüksekti. Ancak kan akımındaki bu artışın uzun dönemde devam etmediği gözlendi.

Serebral oksimetre değerlendirmesi 1,5 . Ve 90.gün VMR testi sirasında yapıldı ve Hb'nin dokuya bıraktığı oksijen saturasyonundaki değişim yüzdeleri hesaplanarak lezyon tarafi, karş1 hemisfer ve iki grup arasında karşılaştırıldı. $\mathrm{Bu}$ karşılaştırma sonucunda elde edilen oksijen saturasyon artışları açısından gruplar arasında anlamlı farklılık saptanmadi. Bu durum kan akım hızlarındaki değişimlerin $\mathrm{Hb}$ 'nin dokuya bıraktığı oksijen saturasyonunu çok etkilemediğini göstermektedir.

Hemodilüsyon uygulanan hastaların hiçbirinde anaflaktik reaksiyon gelişmedi, böbrek yetmezliği ya da başka bir yan etki gözlenmedi. Mortaliteye bakıldığında çalışmaya katılan hastalardan hepsi $\mathrm{HG}^{\prime} \mathrm{de}$ olmak üzere 4'ü tanesi eks oldu ancak mortalite nedeni hemodilusyon olarak değil büyük alan infarktına ve başlangıçtan itibaren kötü klinik skorlara sahip olması ile intraserebral olayın bir sonucu olarak değerlendirildi.

\section{Sonuç}

Hemodilüsyonun, VMR test sonuçlarında ve oksijen dağılım yüzdelerinde uygulama zamanına ve kontrol grubuna göre anlamlı bir fark oluşturmadığı gözlendi. Ancak klinik olarak HG'de 90.gün SSS, MCANS skorlarında gözlenen anlamlı düzelme, hemodilüsyonun kronik dönemde klinik iyileşme üzerinde olumlu etkisi olduğunu düşündürmektedir.

\section{KAYNAKLAR}

1. Feng R, Badgeley M, Mocco J, Oermann EK. Deep learning guided stroke management: a review of clinical applications. $J$ Neurointerv Surg 2018;10:358-62

2. Torun S. Hemoreolojik yaklaşımlar. Özdemir G. İskemik strok akut tedavi ilkeleri. Beyin Damar Hastalıkları Derneği Yayın no:2, 1995, 47-58
3. Tu YK, Heros RC, Karacostas D et al. Isovolomic hemodilution in experimental focal cerebral ischemia part 2: effect on regional cerebral blood flow and size of infarction. $J$ Neurosurg 1988;69:82-91

4. Chang CK, Chien CH, Chou HL, Lin MT. The protective effect of hipervolemic hemodilution 
in experimental heart stroke. Shock 2001;16:153-58

5. Lin SZ, Chiou TL, Song WS, Chiang YH. Isovolomic hemodilution normalizes the prolonged passage of red cells and plasma through cerebral micro vessels in the partially ischemic forebrain of rats. J Cereb Blood Flow Metab 1996; 16: 280-89

6. Schell RM, Cole DJ, Schultz RL, Osborne TN. Temporary cerebral ischemia effects of pentastarch of albumin on reperfusion injury. Anesthesiology 1992;77:86-92

7. L. Xiong, C. Lei, Q. Wang, W. Li. Acute normovolemic hemodilution with a novel hydroxyethyl starch $(130 / 0,4)$ reduces focal cerebral ischemic injury in rats. European Journal of Anesthesiology 2008; 25: 581-88

8. Perez- Trepichio AD, Furlan AJ, Little JR, Jones SC. Hydroxyethyl starch 200/0,5 reduces infarct volüme after embolic stroke in rats. Stroke 1992;23:1782-1790

9. Sacco S, Marini C, Olivieri L, Pistoia F, Carolei A. Contribution of hematocrit to early mortality after ischemic stroke. Eur Neurol 2007;58:233-8

10. Lee SH, Heros RC, Mullan JC, Karosue K. Optimum degree of hemodilution for brain protection in a canine model of focal cerebral ischemia. J Neurosurg 1994;80:469-73

11. Belayev L, Busto R, Zhao W, Clemens JA, Ginsberg MD. Effect of delayed albümin hemodilution on infarction volüme and brain edema after transient middle cerebral arter occlusion in rats. J Neurosurg 1997;87:595601

12. Goulin GD, Duthie SE, Zornow MH, Scheller MS, Peterson BM. Global cerebral ischemia effects of pentastarch after reperfusion. Anesth Analg 1994;79:1036-1042

13. Ohtaki M, Trammer BI. Role of hypervolemic hemodilution in focal cerebral ischemia of rats. Surg Neurol 1993; 40: 196-206

14. Goslinga H, Eijzenbach V, Heuvelmans JH, Van-der-Laan-de-Vries-E, Melis UM, Schmid
Schonbein H, Bezemer PD. Custom-tailored hemodilution with albümin and crystalloids in acute ischemic stroke. Stroke 1992;23:181-8

15. Mast H, Marx P. Neurological deterioration under isovolemic hemodilution with hydroxyethylstarch in acute cerebral ischemia. Stroke. 1991;22:680-83

16. Asplund $\mathrm{K}$, Israelsson $\mathrm{K}$, Schampi I. Hemodilution for acute ischemic stroke. Cochrane Database Syst Rev 2000; CD000103

17. Edward C. Jauch et al. Guidelines for the early management of patients with acute ischemic stroke. Stroke. 2013;44:870-947

18. Chang TS, Jensen MB. Hemodilution for acute ischemic stroke. Cochrane Database Syst Rev. 2014(8) CD000103 Stroke 2015;46:4-e5

19. Tu YK, Heros RC, Candis G, Hyoda A, Lagree K, Callahan R, Zerves NT, Karacostas D. Isovolemic hemodilution in experimental focal cerebral ischemia effect on hemodynamics, hemorheology and intracranial pressure. J Neurosurg 1988;69:72-81

20. Wood JH, Simeone FA, Fink EA, Golden MA. Hypervolemic hemodilution in experimental focal cerebral ischemia. Elevation of cardiac ouput, regional cortical blood flow and ICP after intravascular volüme expansion with low molecular weight dextran. J Neurosurg 1983;59:500-509

21. Kellert L. Et al. Cerebral oxygen transport failure: Decreasing hemoglobin and hematocrit levels after ischemic stroke predict poor outcome and mortality. Stroke 2011; 42: 2832-37

22. Hemodilution in stroke study group. Hypervolemic hemodilution treatment of acute stroke. Results of a randomized multicenter trial pentastarch. Stroke 1989; 20: 317-323

23. Miller JB, Lewandowski C, Wira CR, Taylor A, Burmeister C, Welch R. Volume of plasma expansion and functional outcomes in stroke. Neurocrit Care 2017; 26: 191-95 